This item was submitted to Loughborough's Research Repository by the author.

Items in Figshare are protected by copyright, with all rights reserved, unless otherwise indicated.

\title{
What is the source level of pile-driving noise in water?
}

\section{PLEASE CITE THE PUBLISHED VERSION}

http://dx.doi.org/10.1007/978-1-4419-7311-5_100

\section{PUBLISHER}

(C) Springer Science+Business Media

\section{VERSION}

AM (Accepted Manuscript)

\section{LICENCE}

CC BY-NC-ND 4.0

\section{REPOSITORY RECORD}

Lepper, Paul A., Christ A.F. de Jong, Stephen P. Robinson, and Michael A. Ainslie. 2019. "What Is the Source Level of Pile-driving Noise in Water?". figshare. https://hdl.handle.net/2134/9513. 
This item was submitted to Loughborough's Institutional Repository (https://dspace.lboro.ac.uk/) by the author and is made available under the following Creative Commons Licence conditions.

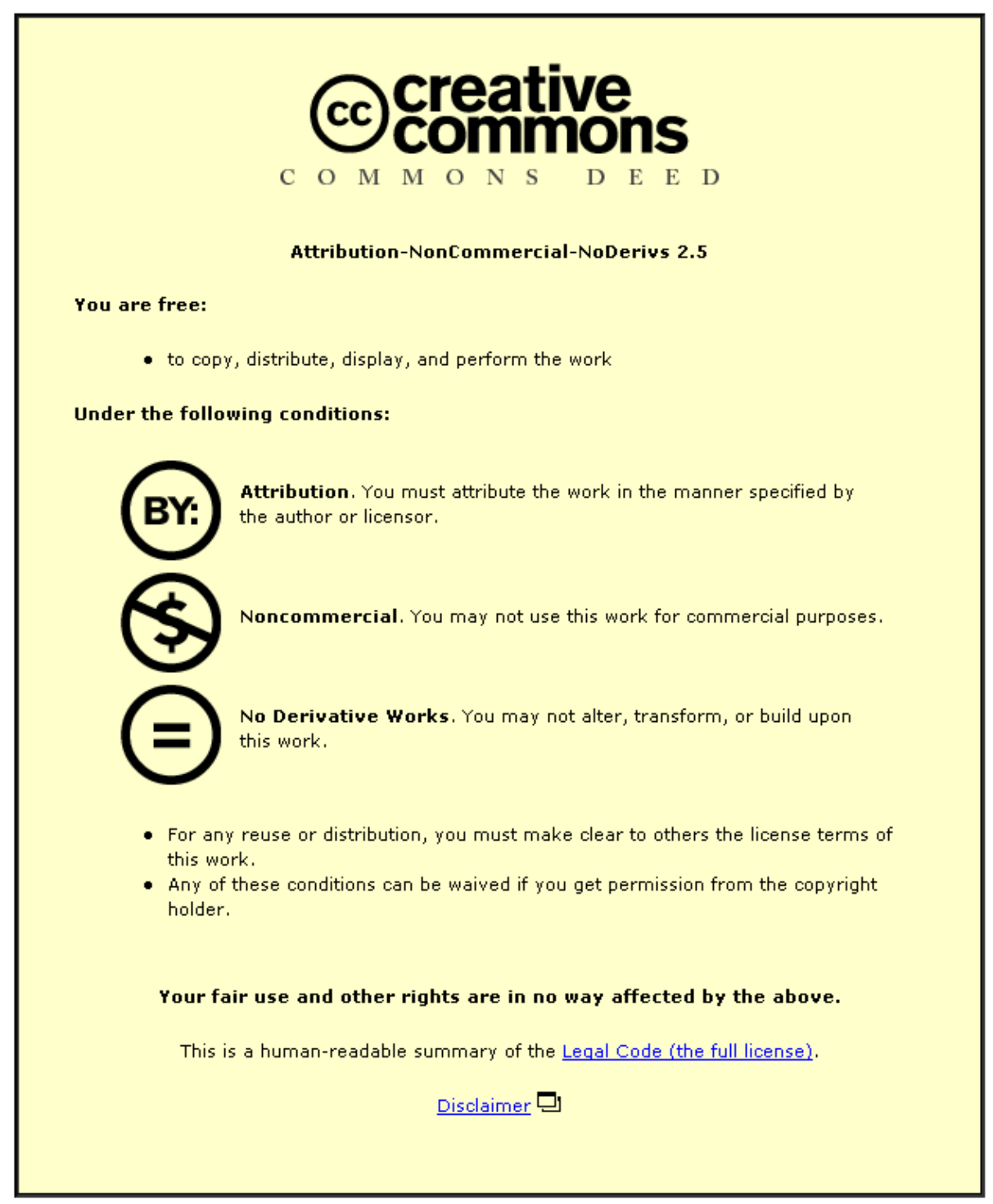

For the full text of this licence, please go to: http://creativecommons.org/licenses/by-nc-nd/2.5/ 


\title{
What is the Source Level of Pile Driving Noise in Water?
}

\author{
Michael A Ainslie ${ }^{1}$, Christ A F de Jong ${ }^{2}$, Stephen P Robinson ${ }^{3}$, Paul A Lepper ${ }^{4}$ \\ ${ }^{1}$ TNO Sonar Department, The Hague, The Netherlands, michael.ainslie@tno.nl \\ ${ }^{2}$ TNO Monitoring Systems, Delft, The Netherlands, christ.dejong@tno.nl \\ ${ }^{3}$ National Physical Laboratory, Teddington, Surrey, UK, stephen.robinson@npl.co.uk \\ ${ }^{4}$ Loughborough University, Loughborough, UK, p.a.lepper@lboro.ac.uk
}

\section{Introduction}

To meet the growing demand for carbon-free energy sources, the EU has ambitious plans to increase its capacity for generation of offshore wind power. The UK and Netherlands, for example, plan to increase their offshore power generating capacity, respectively, to 33 and 6 gigawatts by the year 2020. Assuming that this power is generated entirely by wind, and that a single wind turbine can generate up to $10 \mathrm{MW}$, at least 3900 offshore turbines would be required by these two states alone to achieve this goal. A popular turbine construction method, known as "pile driving", involves the use of hammering a steel cylinder (a "monopile") into the seabed. A concern has arisen for the possible effect on mammals (Southall et al. 2007) and fish (Popper and Hastings 2009) of the sound produced by the succession of hammer impacts required to sink the pile to its required depth (tens of metres).

The EU plans to meet this concern by monitoring the sound of impulsive sound sources, including pile drivers, although a consensus has not yet developed over the most appropriate acoustic metric to be used. It is impractical to measure sound at every point where an animal might be, so it makes sense instead to characterise the source in such a way that its impact can be estimated by modelling. It is conventional to parametrise a source of underwater sound by means of its "source level", which is a measure of 
its radiated power or energy. We describe difficulties associated with both the meaning (Sec. 2) and measurement (Sec. 3) of source level in this context. Results are presented in Sec. 4. Environmental impact is addressed in a companion paper (Lepper et al. 2010).

\section{Definitions}

We adopt standard definitions (Morfey 2001), in terms of the acoustic pressure $p(t)$ during a time period $T$, of sound exposure level: $\operatorname{SEL}(T) \equiv 10 \log _{10}\left[E(T) /\left(\mu \mathrm{Pa}^{2} \mathrm{~s}\right)\right]$, where $E$ is the sound exposure $E(T)=\int_{0}^{T} p^{2} \mathrm{~d} t ;$ sound pressure level: $\operatorname{SPL}(T) \equiv 10 \log _{10}\left[(E(T) / T) /\left(\mu \mathrm{Pa}^{2}\right)\right] ;$ and peak pressure: $p_{\text {peak }} \equiv \max |p(t)|$. No frequency weighting is applied. Source level is sometimes defined as the SPL at a distance of $1 \mathrm{~m}$ from the source. Alternatively, it can be defined in terms of the product of the distance $s$ from the source and RMS pressure at that distance, measured in the far field and in free-field conditions, denoted $p_{\mathrm{FF}}(s)$ (Morfey 2001): $\mathrm{SL}_{\mathrm{RMS}} \equiv 10 \log _{10}\left[p_{\mathrm{FF}}(s)^{2} s^{2} /\left(\mu \mathrm{Pa}^{2} \mathrm{~m}^{2}\right)\right]$. Because of the $s^{2}$ scaling and its far-field nature, this quantity is more closely related to the (free-field) radiated power than to intensity (or mean square pressure). It is equal to SPL at $1 \mathrm{~m}$ only in very special conditions (de Jong et al. 2010). For transient sources, such as a pile driver, the averaging time for $\mathrm{SL}_{\mathrm{RMS}}$ is not well defined, so it is useful instead to define an energy source level, $\mathrm{SL}_{\mathrm{E}}$, in terms of the far-field (and free-field) sound exposure $E_{\mathrm{FF}}$,

and scaled by $s^{2}$ in the same way, that is, $\mathrm{SL}_{\mathrm{E}} \equiv 10 \log _{10}\left[E_{\mathrm{FF}}(s) s^{2} /\left(\mu \mathrm{Pa}^{2} \mathrm{~s} \mathrm{~m}^{2}\right)\right]$. The definition of propagation loss to an arbitrary position $\mathbf{x}$ relevant to a transient signal is

$$
\operatorname{PL}(\mathbf{x}) \equiv \operatorname{SL}_{\mathrm{E}}-\operatorname{SEL}(\mathbf{x})
$$




\section{Method and Measurements}

Measurements are made of sound exposure level in third-octave bands as a function of distance from the pile driver. Use of Eq. (1) makes it possible to estimate $\mathrm{SL}_{\mathrm{E}}$ from a measurement of SEL and a model calculation of PL. If the duration $\delta t$ of the transmitted pulse is known (at the sound source), $\mathrm{SL}_{\mathrm{RMS}}$ can be

estimated using $\mathrm{SL}_{\mathrm{RMS}} \approx \mathrm{SL}_{\mathrm{E}}-10 \log _{10}[\delta t / 1 \mathrm{~s}]$. However, it is not clear how this duration can be estimated. It cannot be measured at the source. Similarly, no simple and unambiguous conversion to a source level defined in terms of peak pressure $\left(\mathrm{SL}_{\text {peak }}\right)$ is known to the authors. We therefore limit our attention to the energy source level $\mathrm{SL}_{\mathrm{E}}$, which we calculate by rearranging Eq. (1)

Various models are available for the calculation of underwater acoustic propagation loss. The sound source is commonly modelled as a point monopole that, for simplicity, is assumed to not be in contact either with the sea surface or the seabed. While hiding the real problem under the carpet (the real source passes through the sea surface and is in firm contact with the seabed), this pragmatic approach is adopted here in order to make some progress. Uncertainty in the estimated source level associated with imperfectly known conditions is estimated by means of parameter variations. The risk of modelling error is mitigated by checking selected calculation results against the results of high-fidelity propagation models.

Inputs for the source level calculations are data from measurements of offshore piling activities in The Netherlands (NL) (de Jong and Ainslie 2008) and the UK (Robinson et al. 2007). In these studies, a similar hydraulic piling hammer was used at the same nominal energy of $800 \mathrm{~kJ}$ per stroke. The pile diameters $(\phi)$ were $4 \mathrm{~m}(\mathrm{NL})$ and $2 \mathrm{~m}(\mathrm{UK})$. At the UK site the water depth (denoted $H$ ) varies between 8 and $15 \mathrm{~m}$, depending on local variations and the tide, and the sediment mostly consists of chalk. The water depth at the NL site (Q7) is about $21 \mathrm{~m}$, with a relatively flat, sandy bottom. 


\section{Results}

Comparing the underwater noise produced at various piling sites does not require an estimation of source level (SL). Interpolation or extrapolation of measurement data to the received SEL at a standard distance, e.g., $750 \mathrm{~m}$ (the reference distance for evaluating piling noise that is currently applied by the German government), introduces less uncertainty than the SL estimation. However, the advantage of SL estimations is that these can be used as input for prediction models, e.g., to produce noise maps.

Figure 1 gives an estimate of the $\mathrm{SL}_{\mathrm{E}}$ spectrum for NL site $\mathrm{Q} 7$, for various choices of the environmental conditions, using an implementation of Weston's flux method (Weston, 1976), with all measurement points in the 'mode stripping' region. The curves represent the power averaged levels found from applying Eq. (1) to the various measurement results. The large variations at higher frequencies are relevant for the prediction of the impact of piling noise on marine species which have a high frequency hearing sensitivity (especially "HF cetaceans", Southall et al. 2007). The total broadband $\mathrm{SL}_{\mathrm{E}}$ of these spectra varies between 215 and $220 \mathrm{~dB}$ re $1 \mu \mathrm{Pa}^{2} \mathrm{~m}^{2} \mathrm{~s}$, with most of the energy in the frequency range 100-500 $\mathrm{Hz}$. Measurement distances from the pile were between 0.9 and $5.6 \mathrm{~km}$. 


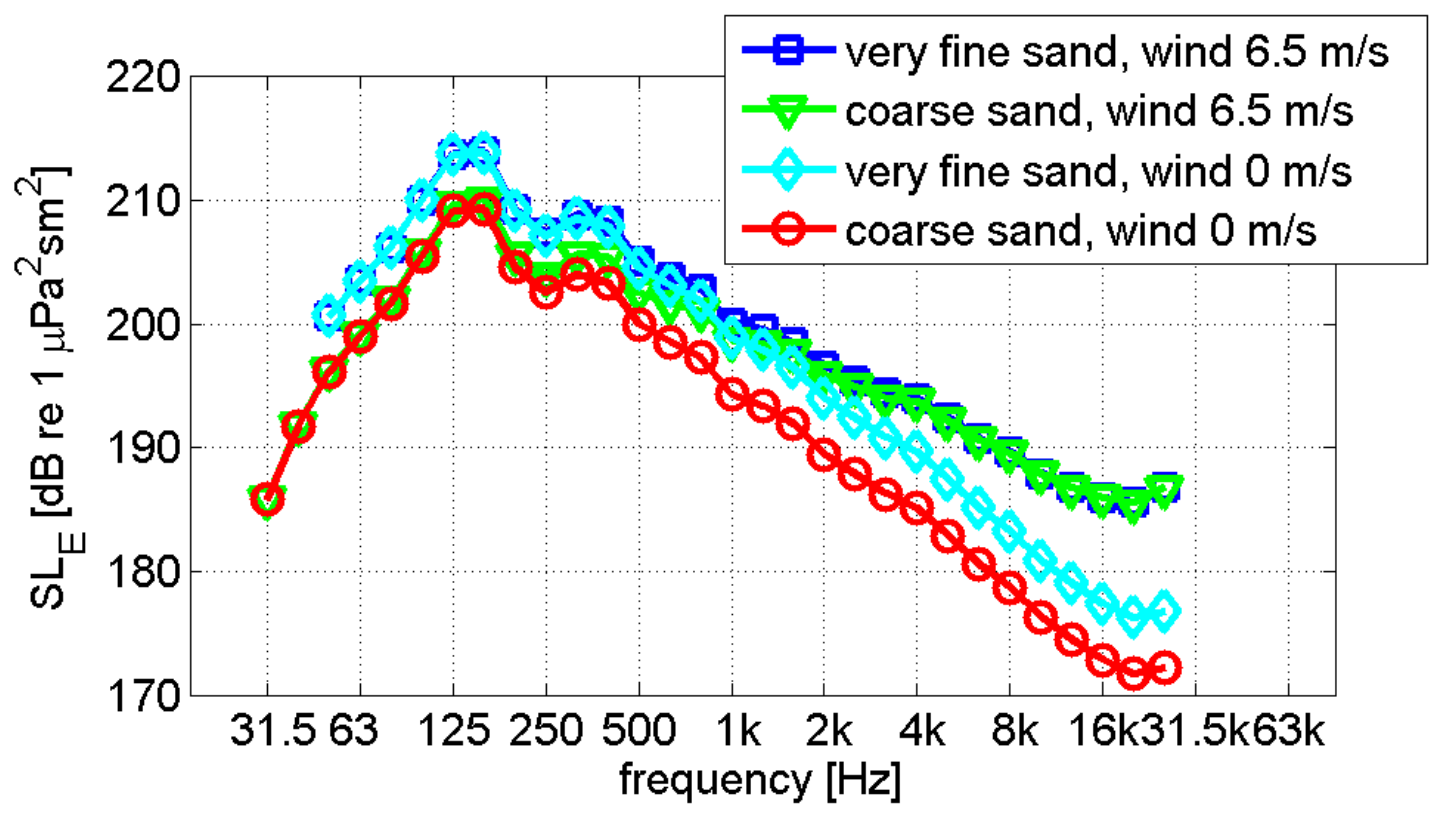

Fig. 1. Third-octave energy source level spectra estimated for NL site: $\phi=4 \mathrm{~m}$; hammer energy $=800 \mathrm{~kJ}$.

At the UK site, broadband SELs of 178 and $164 \mathrm{~dB}$ re $1 \mu \mathrm{Pa}^{2} \mathrm{~s}$ were observed at distances of $57 \mathrm{~m}$ and $1850 \mathrm{~m}$, respectively. Interpolation between measurement results at Q7 leads to an estimated SEL of 168 $\mathrm{dB}$ re $1 \mu \mathrm{Pa}^{2}$ s at $1850 \mathrm{~m}$, i.e., $4 \mathrm{~dB}$ above the SEL observed at the UK site. Applying Eq. (1) to the UK measurements yields $\mathrm{SL}_{\mathrm{E}}$ in the range 204.5 to $213.5 \mathrm{~dB}$ for $\phi=2 \mathrm{~m}$ and hammer energy $800 \mathrm{~kJ}$.

\section{Conclusions}

We sidestep fundamental questions concerning the definition of "source level" by idealising the monopile as a single point monopole that is not in contact with either boundary. Applying the energy conservation principle we obtain values for the energy source level $\left(\mathrm{SL}_{\mathrm{E}}\right)$ between 204.5 and $213.5 \mathrm{~dB}$ re $\mu \mathrm{Pa}^{2} \mathrm{~m}^{2} \mathrm{~s}$ for the UK site ( $\phi=2 \mathrm{~m}, H=21 \mathrm{~m}$, chalk) and between 215 and $220 \mathrm{~dB}$ for the NL site $(\phi=4 \mathrm{~m}, H=8-15$ $\mathrm{m}$, sand), both for a hammer energy of $800 \mathrm{~kJ}$. This range of $\mathrm{SL}_{\mathrm{E}}$ estimations converts (de Jong and Ainslie 2008) to an acoustic source energy of 2.3 to $18 \mathrm{~kJ}$ per piling stroke for the UK site and 26 to $82 \mathrm{~kJ}$ 
(NL site). Thus, for the situations considered the energy radiated as sound is between 0.3 to 10 percent of the total stroke energy.

An estimate of $\mathrm{SL}_{\mathrm{RMS}}$ is possible, but only if the duration of the transmitted pulse is known or estimated. An estimate of $\mathrm{SL}_{\text {peak }}$ is beyond the present scope, as this requires a detailed understanding of the sound generation mechanism, and time domain modelling of the radiated waveform.

Further research is needed to study radiation mechanisms. An internationally accepted standard definition of SL is urgently needed, in order to facilitate comparison between measurements made using different methods, especially if source levels are expressed in the form of RMS or peak pressure.

\section{References}

de Jong CAF, Ainslie MA (2008) Underwater radiated noise due to the piling of the Q7 Offshore Wind Park. In: Zakharia M (ed) Proceedings of the European Conference on Underwater Acoustics, Acoustics'08, Paris, France, pp 117-122.

de Jong CAF, Ainslie MA, Blacquière G (2010) Measuring underwater sound: towards measurements standards and noise descriptors. TNO-DV 2009 C613, TNO, The Hague, Netherlands.

Lepper PA, Robinson SP, Theobald PD, Ainslie MA, de Jong CAF (2010) Assessment of cumulative Sound Exposure Level (SEL) for marine piling events. In this volume.

Morfey CL (2001) Dictionary of Acoustics. Academic, San Diego.

Popper AN, Hastings MC (2009) The effects of anthropogenic sources of sound on fishes. Journal of Fish Biology 75: 455-489.

Robinson SP, Lepper PA, Ablitt J (2007) The measurement of the underwater radiated noise from marine piling including characteristics of a "soft start" period. In: Proceedings of the IEEE Oceans 2007 Conference, Aberdeen, UK, 061215-074 pp 1-6. 
Southall BL, Bowles AE et al. (2007) Marine mammal noise exposure criteria: Initial scientific recommendations. Aquatic Mammals 33 (4): 411-521.

Weston DE (1976) Propagation in water with uniform sound velocity but variable-depth lossy bottom. J Sound Vib 47(4): 473-483.

\section{FIGURE LEGENDS}

Fig. 1. Third-octave energy source level spectra estimated for NL site: $\phi=4 \mathrm{~m}$; hammer energy $=800 \mathrm{~kJ}$ 